\title{
Glauber en trance: el tiempo como dimensión social en la poesía de Paulo Martins ${ }^{1}$
}

\author{
Entranced Glauber: Time as social dimension in Paulo Martins's poetry
}

\author{
Manuel Barrós \\ Pontificia Universidad Católica del Perú, Lima, Perú \\ Contacto:mfbarrosa@pucp.pe \\ https://orcid.org/0000-0003-2176-6059
}

\begin{abstract}
Resumen
En el presente estudio analizo el tiempo como dimensión social en la estética de Terra em transe (1967) a través de la poesía de Paulo Martins, alter ego de Glauber Rocha. A partir de las ideas de Brecht propongo que el lenguaje poético verbal tuvo una gran importancia, pues mediante sus representaciones temporales se puede rastrear su relevancia lírica: por su dramaticidad y capacidad de transmitir los tránsitos emocionales y oscilaciones políticas del protagonista. Al analizar su especificidad estética, ésta remite a su compleja relación con los otros lenguajes comprendidos en el registro fílmico y aportes a la realización de la película en el contexto de la dictadura militar brasileña (1964-1985).
\end{abstract}

Palabras clave: Glauber Rocha; Terra em transe; Dictadura militar brasileña; Estética marxista; Cine; Poesía

\begin{abstract}
In this paper I analyse the time as a social dimension in the aesthetic of Terra em transe (1967) through Paulo Martin's poetry, Glauber Rocha's alter ego. From Brecht's theoretical ideas, I propose that verbal poetical language was very important because through its representations of time I can study its lyrical relevance: its dramatic quality and its capacity to show the emotional transitions and political movements of the protagonist. At the moment I analyse its aesthetics specificity, this one makes me think in its complex relations with other artistic languages involved on the film and its contributions to achieve the film in the Brazilian military dictatorship context (1964-1985).
\end{abstract}

Keywords: Glauber Rocha; Entranced earth; Brazilian military dictatorship; Marxism aesthetics; Poetry; Cinema

Recibido: $16.08 .17 \quad$ Aceptado: 30.04 .18 
A política e a poesia são demais para um homem só.

Sara

\section{El hambre de Glauber}

Terra em transe (1967) es una película que comprende muchas capas estéticas en su reflexión social, política y cultural. Se constituyó como la obra principal del Cinema Novo por su forma artística, dada la manera peculiar en que fueron empleados los recursos técnicos y por su contenido social, ya que comprendió los diálogos sociales de una época. En un periodo histórico marcado por la dictadura militar (1964-1985), que redefinió los paradigmas de la sociedad y el proyecto de nación en Brasil, Glauber Rocha $(1963,2004)$ se posicionó con su obra al hablar sobre sus propias preocupaciones y las de su generación ${ }^{2}$. En dicho contexto, la película como producción artística es una representación de su realidad inmediata y una manera de experimentar ese tan agitado tiempo social de cambios que fue la dictadura (Araújo, 2006). Por eso mismo, Glauber no recreó un pasado distante, sino un presente muy tangible, concretizando un hecho estético: Terra em transe fue una experiencia social — y estética — para Brasil como fuente y platea de sus propias representaciones.

El cine de Glauber Rocha (1938-1981) fue un proyecto político. Siguiendo una línea brechtiana, su producción artística buscó ser un cine de demolición ideológica por su filiación a las ideas del teatro épico ${ }^{3}$. Desde el inicio Glauber procuraba la des-seducción y el aturdimiento de un público acostumbrado a las fórmulas "hechas" y "vacías" en el cine (Sánchez, 2000). Brecht buscaba la concientización del público sobre las condiciones sociales de vida para generar una posición crítica a favor de la acción revolucionaria. Para él, la tarea del artista "no es solo la de representar el mundo, sino que debe denunciar las estructuras preconcebidas — bien sean lingüísticas, sociales o técnicas - a la hora de hacer arte" (Burón, 2013, p. 10). En esos postulados, el distanciamiento era el elemento constitutivo de dicha toma de consciencia, para que el espectador pueda "separarse" de los fenómenos que experimentó en el escenario y, así, construir "un significado propio de la obra" (Brecht, 2004, p. 50). 
Tras un periodo formalista, el cine de Glauber Rocha procuró referirse directamente a la realidad brasileña, buscando su transformación. Luego de realizar varias películas de ficción y no-ficción, hacia 1964 en Brasil terminó el periodo democrático y los recursos del Glauber se dirigieron a evidenciar una dictadura opresora a la que, en 1967, presentaría Terra em transe. Este filme cuenta la trayectoria de Paulo Martins, poeta, periodista y aspirante político; una historia de delirio y agonía donde el martirio existencial de cada decisión define el ritmo oscilante de la película. Describiendo el desaliento del fracaso por todos los altos y bajos en las instancias militantes, emocionales y éticas - "Yo tengo compromisos conmigo mismo", diría-, Paulo será el elemento central para poder afirmar que toda la película es un trance constante no solo de él, sino de todas las dudas del propio Glauber (Xavier, 2003).

La película tiene dos tipos de discurso: el lírico y el político. Ambos me interesan, pues el primero es el modo en que abrazó la historia, el compromiso político y el carácter poético en sus creaciones para reflexionar sobre Brasil; el segundo es colocar "la vida social como drama en el sentido de transformación" (Xavier, 2011). Sin embargo, es en el primer sentido que Paulo puede ser visto como alter ego de Glauber. La poesía

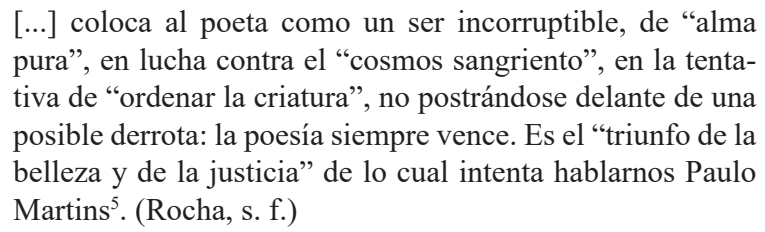

Aunque también tiene que apelar a la violencia, el poeta fue "al menos luz al sur de la tempestad". Cualquier actitud suya a favor o contra el pueblo sirvió para mostrar que la política populista no podía cambiar nada de la situación caótica de El dorado. Por ello, el poeta se volvió un "gladiador difunto, pero intacto": el ideal de "representar bien" la excepción a los posibles errores. Es el poeta como guerrero (ideal romántico): a pesar de ser asesinado, lo que quedó fue la voluntad de guiar al hombre hasta la unidad con el cosmos — en el poema - y de mediar 
entre el hombre y el poder —en la película — ${ }^{6}$ (Rocha, s. f.). Este será el propio trance de Glauber representado en la cinta y también en los elementos que hacen de esta experiencia una síntesis de los dramas de su tiempo: los intentos de Paulo por hacer prevalecer los cuestionamientos y la conciencia social por sobre el romanticismo del poeta (Cândido, 2006; Schwarz, 2005).

\section{Glauber, "Tanta violencia, pero tanta ternura"}

Terra em transe puede ser analizado desde muchas perspectivas. Una de ellas es la del lenguaje cinematográfico — como el recurso poético- que fue utilizado por Glauber para hablar desde el personaje de Paulo Martins, el protagonista, sobre las situaciones límites que lo llevan a aquella idea de "trance". Las metáforas de Glauber para trabajar las crisis sociales y políticas son muy significativas. En sus primeras películas, las locaciones reales eran el nordeste y el sertón, hablando sobre la dificultad de vivir en sociedad, de la fragilidad de los lazos sociales en Brasil como escenario y objeto de percepción (Xavier, 2011). En tal sentido, el espacio imaginario El dorado — país interior y atlántico, según la propia películaes un nuevo centro narrativo donde la angustia social encuentra a Paulo como el protagonista dubitativo y cuestionador sobre lo que hay que cambiar. Paulo es el agente que intenta posicionarse con buenas intenciones y casi un idealismo frente a los políticos de derecha, como Porfirio Díaz, con una trayectoria corrupta, quien lo apadrinó en la juventud y frente a los izquierdistas, como Felipe Vieira, líder populista que procura también el poder. La obra, durante todo su desarrollo, será un trance entre las decisiones poéticas y políticas por las que Paulo optó, una especie de Hamlet social.

El personaje cuenta el propio camino que Glauber tomó en su vida. Xavier (2003; 2011) y otros ya han escrito sobre eso: el tortuoso camino de Terra em transe. En esta cinta, Paulo representa bien los ideales del cineasta:

El héroe glauberiano está siempre delante de un liderazgo político, sea este anclado en el poder religioso, latifundista o incluso en el poder de las milicias populares del cangaço $^{7}$. La estrategia general de sus películas es creencia-descreencia, apego-desapego a los ídolos, a los iconos. (Gardnier, s. f.) 
Sin embargo, ¿cómo es que la poesía de Paulo habla sobre la política y, específicamente, sobre el tiempo social? Aunque el arte tenga siempre una temática universal — vida y muerte, hombre y poder, salvación y perdición, violencia y ternura, etc.- la poesía como manifestación dialoga — ¿qué papel tiene?- con las actitudes individualistas y los equívocos de la política practicada por Paulo ${ }^{8}$. A continuación identifico la poesía en la vida de Paulo.

Uno de los recursos estéticos de la película es la cita de poetas. La primera que Glauber utiliza es un fragmento del poema "Balada" (1966) de Mario Faustino. Pensar en el epígrafe sirve como "índice de valor" sobre lo que es Paulo como personaje-poeta: "El epígrafe encaja perfectamente en Paulo Martins que intenta ser el mediador entre el pueblo que él busca representar y el poder en la figura de Vieira que, por otro lado, también se considera representante del mismo pueblo" (Rocha, s. f.). La segunda referencia es a una copla de Martín Fierro muy próxima a su realidad social: caos, crudeza, violencia, etc. Así, "la importancia de este fragmento en español pasa a tener un significado mayor por la aproximación que esta lengua tiene con una parte del Tercer Mundo, contexto en que Martins, como poeta de El dorado, está inserto" (Rocha, s. f.). Más allá de eso, en el acto de comentar, citando a otros, "Paulo valoriza el comentario y resalta que él, como poeta, se vale de la poesía para todo, hasta para simples constataciones o certezas" (Rocha, s. f.).

Ahora, al hablar sobre la propia poesía de Paulo, se ve su aparición en los momentos existenciales de su vida social, específicamente en los de mayores tensiones políticas:

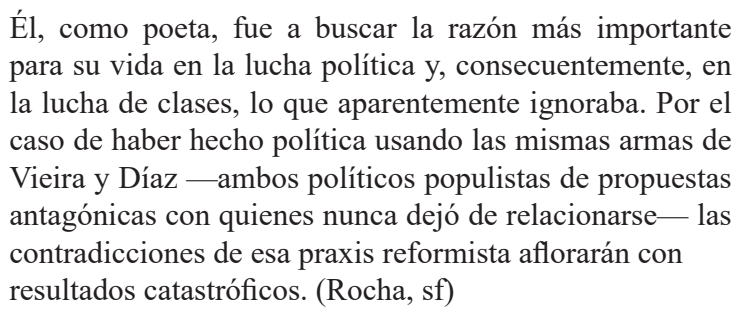

Y es eso mismo lo que lo llevará a un nihilismo absoluto que solo tendrá fin con su muerte. En esa trayectoria, el primer poema de la película aparece cuando Paulo decide abandonar Alecrim y volver a la metrópolis después de renunciar a 
seguir trabajando para Vieira, ya que este no quería asumir las responsabilidades de las promesas de campaña que hizo ${ }^{10}$ Sara aún intentaba persuadir a Paulo: "Me gustaría que te quedaras con nosotros... Vuelve a escribir". Paulo responde:

No anuncio cantos de paz ni me interesan las flores del estilo como por día mil noticias amargas que definen el mundo en que vivo $[\ldots]$

Sara demuestra conocer la producción poética de Paulo y completa lo que parece ser la segunda estrofa de este mismo poema:

Me causan los crepúsculos

el mismo dolor de la adolescencia.

Devuelvo tranquilo al paisaje

los vómitos de la experiencia.

Se trata de un verso "contaminado" por el tedio. El poeta - hombre maduro- reconoce el crepúsculo, el anochecer de las vivencias, el pasar del tiempo y crece con la experiencia (Rocha, s. f.). Se puede decir que el crepúsculo es una metáfora del tiempo. Lo matutino, de luminosidad intensa, está ligado a la adolescencia, y lo vespertino, de luminosidad decreciente, a la experiencia de hombre maduro (Rocha, s. f.). En ambas etapas se encuentra el desasosiego por lo social, la intranquilidad por lo que sucede alrededor, donde la luz sirve como metáfora de la intensidad en la preocupación y memoria por la trayectoria en la dinámica de lo social. El tiempo que él escoge vivir de esa manera es un tiempo social de dolor, de cambio. Las experiencias hasta entonces vividas lo hacen sentirse como una antorcha de luz sin mucho brillo, entediado: en ese hacer se aminora como ser social. Si recuerda lo que sucedió en su vida, el pasado, él está poetizando, en el habla, tiempos simultáneos según la naturaleza de los hechos. Recordar el pasado - la juventud - es, entonces, tener el "beneficio" y "continuidad" del hombre — y del poeta - social en ese recuerdo de la "condición del pasado" (Lowenthal, 1998). Su identidad — de él y su poesía — se define por el "riesgo" de haber recordado ese pasado (Koselleck, 2001). Así, el primer poema muestra el recuerdo, la 
convivencia del pasado con el presente y la preocupación social como constante moral y estética en la trayectoria del poeta.

El segundo poema que aparece en la película tiene como marco que Paulo retoma su producción poética y noches de libido. Luego de experimentar la primera decepción política, él sale de Alecrim y vuelve a la metrópoli. Hospedado en casa de Silvia, su amante, el poeta en el corredor de la pequeña biblioteca dice:

Cuando perdemos nuestra pureza en estos jardines de males tropicales,
cuando en medio de tantos anémicos respiramos
el mismo aliento de los gusanos en tantos poros animales,
o cuando huimos de las calles y dentro de nuestra casa
la miseria nos acompaña en sus cosas más fatales
como la comida, el libro, el disco, la ropa, el plato y la piel
el hígado, de rabia, reventando la garganta en pánico
y un olvido de nosotros inexplicable,
sentimos finalmente que la muerte aquí converge
incluso como forma de vida, agresiva.

Este poema, como todos los otros, se encuentra dentro de la "realidad del vómito" que Paulo Martins propone con su poesía (Rocha, s. f.) ${ }^{11}$. En el juego de imágenes, la crudeza permeable habla sobre las condiciones materiales de existencia en una forma particular de vivir lo social: la miseria. Ya no hay una temática de identidad o recuerdos que lleve a la coexistencia de temporalidades, sino el fatalismo - y casi estoicismo - en lo estético y en lo social en la historia que sucede día tras día: la resistencia y el olvido de sí mismos — el extrañamientoen la vida cotidiana como hecho social. Lo primero, porque esa realidad cruda hace que los hombres que viven en este "jardín de males tropicales", el Tercer Mundo - El dorado o Brasil—, pierdan la pureza. Es decir, el contacto con el pueblo anémico y pobre respirando el "aliento de los gusanos" en las urbes es un camino para descubrir la miseria latente, es convivir con ella; es sentir su presencia como cosas tan reales y tan presentes como "la comida, el libro, el disco, la ropa, el plato y la piel" (Rocha, s. f.). El segundo refiere a la enajenación por no comprender lo que sucede, fácticamente, en las condiciones sociales de vida: en tal sentido es que tiene lugar el "olvido de sí" del que habla Paulo, "el olvido de 
nosotros inexplicable". Así, el segundo poema nos dice sobre un revestimiento temporal del momento en que tiene lugar la historia en lo social y en lo estético, continuando con la preocupación del poeta por la sociedad desde un sentimiento de resistencia y extrañamiento.

El tercer poema aparece en el contexto de la libido de Paulo. Inmediatamente después del poema anterior, el protagonista tiene una escena con Sara y otras mujeres en la que están besándose y bailando jazz. El poeta aparece mirando por la ventana y luego de tocar a Sara, dice:

Mar bravío que me envuelve en este dulce continente.

Puedo morder la raíz de las cañas, la hoja del humo; puedo besar a los dioses, el milagro de mi piel morena-india.

A este olvido puedo donar mi triste voz latina, más triste que revuelta, mucho más.

Vomito en la calle el ácido dólar, avanzando en las plazas entre niños sucios con sus ojos de pájaros ciegos.

Veo que de sangre se dibuja el Atlántico bajo una constante amenaza de metales a propulsión.

Guerras y guerras en los países exteriores.

Puedo añadir que en la luna un astronauta se dio por encontrado.

Todas las bromas son posibles en la tragedia de cada día: yo, por ejemplo, me doy al vano ejercicio de la poesía.

El poeta tiene conciencia de que El dorado no está tan olvidado, pues ve "que de sangre se dibuja el Atlántico / bajo una constante amenaza de metales a propulsión”. Esclarece estar en El dorado (o Brasil) corriendo riesgos de intervención extranjera por las posibles protestas sociales que surjan, "a pesar de la aparente tranquilidad mantenida con hierro y fuego por los dictadores de turno" (Rocha, s. f.). De alguna forma esta situación es extensiva a todos los países del Tercer Mundo que intentan transformar la situación colonial de pobreza y miseria. Pero la referencia al olvido también está en la consciencia de la poesía como forma de existencia y de aproximación a lo político, incluso en los momentos de "desinterés" o de espectador alejado de los acontecimientos sociales: su olvido es su memoria histórica y conciencia de poeta. Hablando de la necesidad de cambiar lo que sucede en la historia del país recuerda la tragedia en la vida social, 
los costos que tiene luchar para reivindicar los derechos del pueblo; no olvida la sangre. Es en la tentativa de volver a su conciencia, por medio de la reflexión del olvido, que lo temporal vuelve desde la perspectiva no militante: hablar sobre el pasado próximo es quedar "sucio de tiempo" —_cada día", "fumo", "tristeza"—, perturbarse de nuevo. Así, como dejó "la militancia de lado, produce un texto de reflexión moderada y que exige una lectura más política, mostrando resultados y preocupaciones colectivas como es el caso de los dos poemas anteriores" (Rocha, s. f.). Antes, cuando él "vomitaba" poemas en el calor de la militancia política, esos exigían una lectura más idealista.

Sin embargo, en los versos de Paulo también se encuentran otros índices temporales. Por ejemplo, aquellos que hacen referencia a los acontecimientos históricos que están desarrollándose en la vida real. "En oposición a la aparente tranquilidad de El dorado (país interior), existen 'guerras y guerras en los países exteriores" (Rocha, s. f.). No hay que olvidar que Terra em transe es contemporáneo a la Guerra de Vietnam y la exploración espacial en un contexto de Guerra Fría; por eso, "en la luna un astronauta se dio por encontrado" (Rocha, s. f.). Otro ejemplo es la reflexión sobre la pertinencia de la poesía en la vida política para reconsiderar la vida burguesa de la cual formó parte: la inutilidad de las palabras y de la poesía. En un mundo donde "todas las bromas son posibles en la tragedia de cada día: / yo, por ejemplo, me doy al vano ejercicio de la poesía”. Aunque se siente desdeñado por el "papel" — del poeta e intelectual que tendría que mediar entre el pueblo y el poder-, él se afirma en la individualidad social del poeta en su estética. Así, el tercer poema se caracteriza por las referencias temporales a la memoria histórica y a la conciencia política como poeta. Ambas hablan sobre él como ciudadano "sucio de tiempo" — perturbado, desasosegado de nuevo-, sobre el carácter realista y universal de sus versos citando acontecimientos de la vida real (fuera de la ficción) y sobre la individualidad en su estética.

El cuarto poema aparece tras la secuencia fílmica "El encuentro con un gran líder", donde se presenta la trayectoria política de Vieira. Paulo Martins, contradictorio, en medio de la muchedumbre dice en off: 


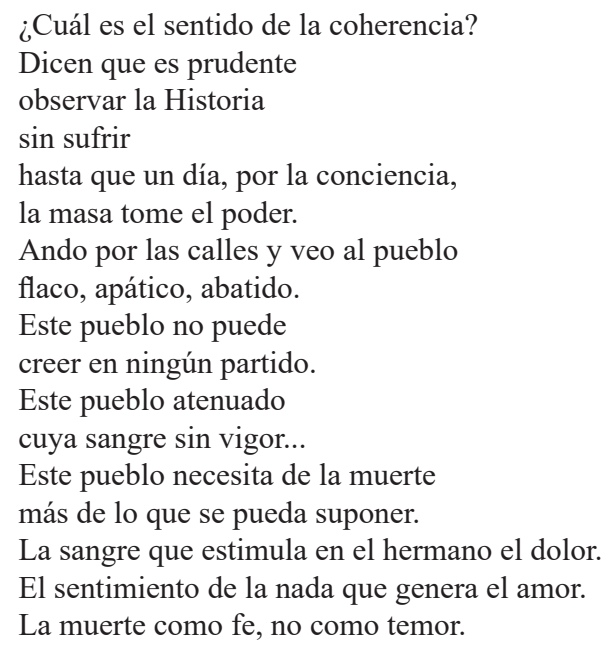

El poema presenta dos significados temporales y estéticos. El primero es el total escepticismo frente al pueblo. "En la primera estrofa el poeta desdeña un pensamiento corriente e histórico, que por la conciencia un día la masa [el pueblo] llegue a ser dueña de su destino, tomando el poder" (Rocha, s. f.). Reafirmando aquí su postura individualista — recuérdese el poema anterior-, él piensa que el pueblo no puede creer en ningún partido porque es "débil, apático" y está "abatido". Aunque él había desarrollado la posición del intelectual al lado de Vieira, conectando el pueblo con los candidatos al poder, en la plaza no percibe al pueblo como una experiencia histórica consciente. Aquí se plasma otra decepción para el poeta. "El pueblo cree en líderes carismáticos y populistas como Vieira que él, como poeta y militante, ayudó a forjar y, si existieran diferentes y libres opciones partidarias, entonces el pueblo pasaría a creer en ellas" (Rocha, s. f.). Por eso, él cree que el pueblo no es la forma social más adecuada para una experiencia histórica consciente y capaz de actuar en su propio destino.

El segundo rasgo es la muerte como forma y resolución de la fatalidad de la vida social. "El total escepticismo de Paulo Martins en la vertiente política adherida al oficialismo que practicó hace que comience a vislumbrar la muerte como única salida redentora, moral y ética para el individuo y para él mismo" (Rocha, s. f.). Por eso declara que "[e]ste pueblo necesita de la muerte / más de lo que se pueda suponer: / la sangre que estimula en el hermano el dolor, / [...] la muerte 
como fe, no como temor" (Rocha, s. f.). Aquí la dimensión temporal es el rechazo por la historia, donde se tiene que aguardar pasivamente a que en algún momento del futuro el pueblo sea el dueño del poder. En tal sentido, en el poema Paulo presenta una estética antiutópica frente a un futuro ideal; y el encuentro de la muerte como salida al tiempo social, a la experiencia histórica que vive.

El último poema aparece en el clímax de la película, en el epílogo. Cuando acaba el flashback, la narrativa retoma a Paulo en el tiempo fílmico presente, agonizante en las dunas, con la ametralladora apuntando al aire: cerrará el discurso de la agonía, del delirio y de la desesperanza. Mientras la película tiene la Bachiana n. ${ }^{\circ} 3$ de Heitor Villa-Lobos como banda sonora, la cámara presenta la coronación de Díaz y en el fondo la voz de Paulo:

No es posible continuar esta fiesta de medallas, esta feliz gala de glorias, esta esperanza dorada en la plana mayor del gobierno.

No, no es posible continuar esta marcha de banderas con Guerra y Cristo en la misma posición.

Así no es posible la impotencia de la fe, la ingenuidad de la fe. Ah, es un terrible tiempo este que no podemos soportar más; que no se puede vivir más en la farsa de un sistema; que aumenta nuestros precios, bebe el zumo de nuestra sangre, destila nuestra paciencia en la carne de nuestros hígados y somos infinita, eternamente Prometeo dilacerado y somos infinita, eternamente hijos del miedo al desangramiento en el cuerpo de nuestro hermano y no asumimos nuestra violencia, no asumimos nuestras ideas con el odio de los bárbaros adormecidos que somos. No asumimos nuestro pasado, todo un raquítico pasado de pereza y de precios en un paisaje de tanto sol sobre almas indolentes, estas indolentes razas de la servidumbre a dios y a los señores, una pasiva fragilidad típica de los indolentes. Ah, no es posible creer que todo esto sea verdad. ¿Hasta cuándo soportaremos; cuánto más allá de la fe y de la esperanza? ¿Soportaremos hasta cuándo más allá de la paciencia y del amor? ¿Soportaremos hasta cuándo más allá de la inconsciencia del miedo, más allá de nuestra infancia y de nuestra adolescencia?

Es el final de Paulo Martins: de sus sueños, tentativas políticas y de su poesía. Él, literalmente, habla sobre la angustia de vivir. Son muchas las construcciones 
verbales que tratan sobre la dificultad de tener sosiego en este tiempo social lleno de sangre, violencia, dolor y sufrimiento personal y social. El juego de imágenes refiere directamente sobre la imposibilidad de una vida social: es la estética del fracaso y de la lucidez de no tener ninguna esperanza en el presente fílmico. Más allá de las referencias explícitas y las metáforas temporales, Paulo se refiere constantemente al país como una situación límite donde algún papel final tiene el discurso poético de un individuo en delirio. "El mensaje disemina desencanto y desesperanza y se torna abarcador, pasando de repente del singular al plural, de lo individual a lo colectivo, de lo particular a lo general" (Rocha, s. f.). Incluso, llega a situar

\footnotetext{
[...] el momento histórico de Paulo Martins que es, al mismo tiempo, el momento histórico de todos los hombres que viven "en la farsa de un sistema que bebe el zumo de nuestra sangre y destila la paciencia en la carne de nuestros hígados". (Rocha, s. f.)
}

Así, finalmente, tenemos el revestimiento temporal y estético de la no-esperanza por ninguna experiencia de tiempo: sea de alguna generación - infancia, adolescencia, etc.—, lugar — Brasil, América — o época — pasado, presente y futuro fílmico- El poeta enumera todos nuestros males y también nos recuerda que no los aceptamos en nosotros mismos. "Paulo Martins ve fracasar su proyecto político. Se alió a corrientes antagónicas, creyó en el liderazgo de varios líderes y se decepcionó de ellos" (Rocha, s. f.). Forzó a Vieira a resistir al golpe inminente. Nada consiguió con la confrontación individual. Paulo agoniza diciendo: "Mi locura es mi conciencia y mi conciencia está aquí: en el momento de la verdad, en la hora de la decisión, en la lucha, incluso en la certeza de la muerte. Debemos resistir, resistir. ¡Yo necesito cantar!”.

\section{Conclusión}

Terra em transe es una película de síntesis: parte de elementos simples — como vivir, hacer poesía - para llegar a otros más complejos como el cuestionamiento de la vida, del acto poético y de las decisiones políticas. Es interesante notar que la obra sintetiza el discurso político en la misma proporción que lo hace con el 
poético. El primero remite a cómo Paulo se plegó a ciertas visiones de sociedad y a los razonamientos y utopías que lo (des)orientaron. El segundo refiere a las discusiones más elaboradas para Paulo como personaje y ser social: el sentido de la vida, la muerte, la miseria; todos temas recurrentes en la poesía del poeta-personaje Martins. Si el tiempo social es construido por medio de nuestras vivencias, cargado de distintas dimensiones sociales, Paulo no solo se encuentra entre varios tiempos sociales, sino que él mismo consigue actuar en su dinámica como agente de cambio en el transcurso de la película. Como he probado líneas arriba, para esta historia la poesía sirve de hilo conductor del melodrama y como recurso que sintetiza el "trance" social de la trayectoria de vida personal y política de Paulo Martins (y de Glauber Rocha).

Recapitulando el análisis hecho, en total son cinco los poemas de Paulo Martins en sus formas estéticas y temporales. El primero muestra el recuerdo, la convivencia del pasado con el presente y la preocupación social como constante moral y estética en la trayectoria del poeta. El segundo poema habla sobre una capa temporal en el momento en que se desarrolla la historia en lo social y en lo estético, y continúa con la preocupación del poeta por la sociedad desde un sentimiento de resistencia y extrañamiento. El tercer poema se caracteriza por las referencias temporales a la memoria histórica, a su conciencia política como poeta: hablan sobre él como ciudadano "sucio de tiempo" — perturbado, desasosegado de nuevo-, sobre el carácter realista y universal de sus versos citando acontecimientos de la vida real — fuera de la ficción - y sobre la individualidad en su estética. En el cuarto, Paulo presenta una estética no-utópica frente a un futuro ideal y el encuentro de la muerte como salida al tiempo social, a la experiencia histórica que vive (Koselleck, 2001; 2006). Finalmente, el quinto habla sobre la capa temporal y estética de la no-esperanza por ninguna experiencia de tiempo de alguna generación —infancia, adolescencia, etc.—, lugar —América- o época - pasado, presente y futuro fílmico- . Así, puedo concluir que la experiencia temporal y el recurso poético en la película hablan sobre el lado artístico, político y emocional del protagonista Paulo Martins, el alter ego de Glauber Rocha. 


\section{Notas}

1. La versión original de este artículo fue escrita en portugués, como trabajo final para el curso História social do tempo de la Faculdade de Filosofia, Letras e Ciências Humanas (FFLCH) de la Universidade de São Paulo, el primer semestre de 2014. El 14 de septiembre de 2016, se presentó como ponencia en el XXI Coloquio de Estudiantes de Literatura Hispánica Est(ética), política e ideología de la Facultad de Letras y Ciencias Humanas de la Pontificia Universidad Católica del Perú.

2. Todas las citas de la película y referencias bibliográficas las colocaré directamente en español, ya traducidas.

3. Leyendo los textos del propio Glauber o las críticas sobre su producción estética, resulta evidente la conexión y las influencias marxistas en el campo de las formas como en los contenidos. Revisar Rocha (2004) y Sánchez (2000).

4. He considerado como poesía los diálogos y monólogos que Glauber hizo con un lenguaje explícitamente poético en la plasticidad de las palabras, como el juego de imágenes, metáforas y la intensidad lírica en ellas.

5. Recuérdase los poemas de Mario Faustino, Martín Fierro o los de Glauber en la escritura del guión de la película.

6. Cuando coloco las palabras entre comillas estoy citando el poema de Mario Faustino que fue referido por Glauber: "No consiguió firmar el noble pacto / Entre el cosmos sangriento y el alma pura / [...] / Gladiador difunto pero intacto / (Tanta violencia, pero tanta ternura)" (Faustino, 1966).

7. El diccionario Priberam define cangaço como "vida de cangaceiro" (en Dicionário Priberam da Lingua Portuguesa [en línea], 2008-2013, http://www. priberam.pt/dlpo/canga\%C3\%A7o [consultado el 08-06-2014]). Y define cangaceiro como "asaltante que recorría el sertón del nordeste brasileño, generalmente en grupos armados, sobre todo al final del siglo XIX y en las primeras décadas del siglo XX" (en Dicionário Priberam da Língua Portuguesa [en línea], 2008-2013, http:/www.priberam.pt/dlpo/cangaceiro [consultado el 0806-2014]).

8. Los otros personajes que participan de la trama política son: Vieira — gobernador de Alecrim, político populista con discurso de contenido "progresista"; D. Porfirio Díaz - senador de la República, político populista con discurso de contenido conservador; Sara — asesora de Vieira; Silvia — hija de D. Porfirio Díaz; Julio Fuentes —empresario nacionalista; Felicio — campesino; Aldo, Álvaro y estudiante — militantes del partido de izquierda; Jerónimo — sindicalista. Y, también, están caracterizados personajes representantes de clases sociales y profesionales como el clero, el ejército, la facción política ligada a la figura de un senador, la prensa, así como figuras de lo que es llamado genéricamente el "pueblo" (Rocha, s. f.). 
9. "Es el pobre en su orfandad / de la fortuna de desecho / porque nadie toma a pechos / el defender a su raza; / debe el gaucho tener casa / escuela, iglesia y derechos" (Martín Fierro, José Hernández).

10. Cronológicamente, en la película el primer poema aparece en una secuencia a poco minutos del inicio, después de que Paulo presencia el discurso que Vieira dicta a Silvia. Pero, como el poema se refiere dos veces, y ya completo en el epílogo de la película, vamos a analizarlo al final.

11. Glauber declara: "Lo que me chocó en el poema de Lautréamont fue una tortura permanente. Hay un realismo de vómito. Me atacaron mucho por causa de la estructura de mi película. Quise darle esa apariencia de vómito". Es una declaración de Rocha a Positif n. ${ }^{\circ}$ 91, Río de Janeiro de 1968; citado por Amengual (1977, p. 106).

\section{Referencias bibliográficas}

Amengual, B. (1977). Glauber Rocha, ou os caminhos da liberdade. En Glauber Rocha. Río de Janeiro, Brasil: Paz e Terra.

Araújo, R. F. (2006). Terra em transe. Río-São Paulo-Fortaleza: ABC Editora.

Brecht, B. (2004). Escritos sobre teatro. Barcelona: Editorial Alba.

Burón, D. R. (2013). El origen del teatro épico. Fundamentos para una práctica revolucionaria. Scientia Helmantica. Revista Internacional de Filosofia de la Universidad de Salamanca, 1(1), 137-163.

Cândido, A. (2006). Literatura e sociedade. Estudos de teoria e história literaria, novena ed. Río de Janeiro: Ouro sobre Azul.

Faustino, M. (1966). Poesía de Mário Faustino. Río de Janeiro: Civilização Brasileira.

Gardnier, R. (s. f.). Deus e o Diabo no mito do Glauber? Recuperado de: http:// www.contracampo.com.br/27/deuseodiabonaterradosol.htm

Koselleck, R. (2001). Los estratos del tiempo: estudios sobre la historia. Barcelona: Paidós.

Koselleck, R. (2006). Futuro passado: contribuição à semântica dos tempos históricos. Río de Janeiro: Contraponto.

Lowenthal, D. (1998). El pasado es un país extraño. Madrid: Akal.

Rocha, A. do A. (s. f.). O poeta vai morrer. Baleia na Rede. Revista online do Grupo de Pesquisa e Estudos em Cinema e Literatura, 163-186. Recuperado de: http://www.marilia.unesp.br/Home/RevistasEletronicas/BaleianaRede/Edicao04/poeta.pdf 
Rocha, G. (1963). Uma estética da fome. São Paulo: [s.r.e.d.]

Rocha, G. (2004). Entrevista a Positify O Cinema Novo e a aventura da criação. En Revolução do Cinema Novo. São Paulo: Cosac \& Naify.

Sánchez, P. A. (2000). Terra em Transe y Panis et circensis. Tropicalismo: decadência bonita do samba, 15-40, 41-50.

Sánchez Vásquez, A. (2004). Las ideas estéticas de Marx. Ciudad de México: Siglo XXI.

Xavier, I. (2003). O olhar e a cena: Melodrama, Hollywood, Cinema Novo e Nelson Rodrigues. São Paulo: Cosac \& Naify.

Xavier, I. (2011). O cinema politico de Glauber: entre o sagrado e o profano. São Paulo: Palestra em Sesc. Recuperado de: https://www.youtube.com/ watch?v=pa7Me-m6zPI

\section{Filmografía}

Rocha, G. (director). (1959). Pátio [Corto cinematográfico]. Brasil: Iglu Filmes.

Rocha, G. (director). (1959). A cruz na praça [Corto cinematográfico]. Brasil: Iglu Filmes.

Rocha, G. (director). (1962). Barravento [Cinta cinematográfica]. Brasil: Iglu Filmes.

Rocha, G. (director). (1964). Deus e o Diabo na Terra do Sol [Cinta cinematográfica]. Brasil: Banco Nacional de Minas Gerais, Copacabana Filmes, Luiz Augusto Mendes Produções Cinematográficas.

Rocha, G. (director). (1965). Amazonas, Amazonas [Corto cinematográfico]. Brasil: s. d.

Rocha, G. (director). (1966). Maranhão 66 [Documental cinematográfico]. Brasil: Mapa Filmes.

Rocha, G. (director). (1967). Terra em transe [Cinta cinematográfica]. Brasil: Mapa Filmes. 